\title{
FLOWERING IN PISUM. A THREE-GENE SYSTEM
}

\author{
I. C. MURFET \\ Botany Department, University of Tasmania, Hobart, Australia
}

Received 28.viii.70

\section{INTRODUCTION}

In an earlier paper (Murfet, 1971) I described how six different phenotypic classes could be recognised amongst a group of 12 pea varieties by observing flowering behaviour under both short and long photoperiods. Analysis of the genetic basis for these differences was commenced by describing a cross in which three distinct phenotypes occurred in the $F_{2}$ in the ratio $4: 9: 3$. In this particular cross the three classes, namely ED, EI and L, were determined by the interaction of two dominant major genes $E$ and $S_{2}$. Genetic analysis of these three classes is continued in this paper. Six further varieties are brought into the crossing programme and it is shown amongst other things that a third major gene $S_{1}$ is also involved.

\section{Materials and Methods}

Flowering node is taken as the first node at which a flower is initiated irrespective of subsequent development counting from the cotyledonary node as zero. Flowering time is taken as days from sowing to first open flower. The classes ED, EI and L may be recognised under short days as follows. ED (early developing) plants are early in node and time (standard variety Line 59), EI (early initiating) plants are early in node but late in time (standard variety Line 60) and L (late) plants are late in node and time (standard variety Line 24). The late flowering time for EI plants under short days occurs because the lower flower buds usually fail to develop into mature flowers. In rare instances development proceeds but at a greatly retarded pace.

Plants were matured under long days or at least natural photoperiod, being maintained under short days either until all plants had initiated flower buds or in some crosses until a minimum of 15 nodes were expanded. The latter procedure will permit separation of the classes but may slightly truncate the late end of the distribution and small samples were maintained in short days to check on extreme segregates. These procedures freed short day space as well as providing conditions more favourable to seed set and ripening. Unless otherwise stated it may be assumed that parents $F_{1}$ and $F_{2}$ have been grown at the same time using a randomised block design.

Line 22 was developed from a dozen seeds of the commercial variety Massey. It proved to be impure at the $E$ locus. Line 59 and Line 24 are single plant selections from cv. Massey and cv. Greenfeast respectively. Line 2 is a grey dwarf. Line 8 is a cryptodwarf developed by Rasmusson from a cross between Line 2 and Witham Wonder. Lines 58, 60 and 61 were developed during the crossing programme, Line 58 from Cross 50 and Lines 60 and $6 \mathrm{I}$ from Cross 57. Line $6 \mathrm{l}$ is $\mathrm{L}$ type on major gene content but a high level of penetrance modifiers results in a proportion of EI as well as L plants. 
Further information on growing conditions, scoring procedures, the varieties used and the scheme of phenotypic classification may be found in Murfet (1971).

\section{Results}

The results of Cross 20 were given in Murfet (1970), but this cross forms an integral part of the crosses reported here and the results are referred to

\section{TABLE 1}

The parental phenotypes and their proposed genotypes, the crosses made and the predicted $F_{1}$ and $F_{2}$ phenotypes with their expected proportions

\begin{tabular}{|c|c|c|c|c|c|c|}
\hline $\begin{array}{l}\text { Line } \\
\text { Phenotype } \\
\text { Genotype }\end{array}$ & $\begin{array}{c}2 \\
\mathrm{~L} \\
S_{1} E S_{2}\end{array}$ & $\begin{array}{l}8,60 \\
\mathrm{EI} \\
s_{1} E S_{2}\end{array}$ & $\begin{array}{c}24 \\
\mathrm{~L} \\
S_{1} e S_{2}\end{array}$ & $\begin{array}{c}53,61 \\
\mathrm{~L} \\
s_{1} e S_{2}\end{array}$ & $\begin{array}{l}22,59 \\
\mathrm{ED} \\
s_{1} E s_{2}\end{array}$ & $\begin{array}{l}22,58 \\
\text { ED } \\
s_{1} e s_{2}\end{array}$ \\
\hline $\begin{array}{l}2 \\
\mathrm{~L} \\
S_{1} E S_{2}\end{array}$ & $\begin{array}{l}\text { Cross no. } \\
\text { Parents } \\
\mathrm{F}_{1} \\
\mathrm{~F}_{2} \text { ED:EI:L }\end{array}$ & $\begin{array}{l}\mathrm{C} 26(2 \times 8) \\
\mathrm{L} \times \mathrm{EI} \\
\mathrm{L} \\
0: 1: 3\end{array}$ & $\begin{array}{l}\text { Not made } \\
\mathrm{L} \times \mathrm{L} \\
\mathrm{L} \\
0: 0: 1\end{array}$ & $\begin{array}{l}\mathrm{C} 57(2 \times 53) \\
\mathrm{L} \times \mathrm{L} \\
\mathrm{L} \\
0: 3: 13\end{array}$ & $\begin{array}{l}\mathrm{C} 53(2 \times 22) \\
\mathrm{L} \times \mathrm{ED} \\
\mathrm{L} \\
4: 3: 9\end{array}$ & $\begin{array}{l}\text { Not made } \\
\mathrm{L} \times \mathrm{ED} \\
\mathrm{L} \\
16: 9: 39\end{array}$ \\
\hline & & & C2 $(8 \times 24)$ & $\begin{array}{l}\text { C114 }(60 \times 53) \\
\text { C126 }(8 \times 53)\end{array}$ & Not made & C127 $(8 \times 58)$ \\
\hline $\begin{array}{l}8,60 \\
\mathrm{EI} \\
s_{1} E S_{2}\end{array}$ & E & E & $\begin{array}{l}\mathrm{EI} \times \mathrm{L} \\
\mathrm{L} \\
0: 3: 13\end{array}$ & $\begin{array}{l}E I \times L \\
E I \\
0: 3: 1\end{array}$ & $\begin{array}{l}\mathrm{EI} \times \mathrm{ED} \\
\mathrm{EI} \\
1: 3: 0\end{array}$ & $\begin{array}{l}E I \times E D \\
\text { EI } \\
4: 9: 3\end{array}$ \\
\hline $\begin{array}{l}24 \\
\mathrm{~L} \\
S_{1} e S_{2}\end{array}$ & $\overline{-}$ & - & $\overline{-}$ & $\begin{array}{l}\mathrm{C} 40(24 \times 53) \\
\mathrm{L} \times \mathrm{L} \\
\mathrm{L} \\
0: 0: 1\end{array}$ & $\begin{array}{l}\text { Not made } \\
\mathrm{L} \times \mathrm{ED} \\
\mathrm{L} \\
16: 9: 39\end{array}$ & $\begin{array}{l}\mathrm{C} 125(24 \times 58) \\
\mathrm{L} \times \mathrm{ED} \\
\mathrm{L} \\
1: 0: 3\end{array}$ \\
\hline & & & & & C20 $(53 \times 59)^{*}$ & $\begin{array}{l}\text { C50 }(53 \times 22) \\
\text { C119 }(61 \times 22)\end{array}$ \\
\hline $\begin{array}{l}53,61 \\
\mathrm{~L} \\
s_{\mathbf{1}} e S_{2}\end{array}$ & - & E & I & E & $\begin{array}{l}L \times E D \\
\text { EI } \\
4: 9: 3\end{array}$ & $\begin{array}{l}\mathrm{L} \times \mathrm{ED} \\
\mathrm{L} \\
1: 0: 3\end{array}$ \\
\hline $\begin{array}{l}22,59 \\
\mathrm{ED} \\
s_{1} E s_{2}\end{array}$ & E & $\begin{array}{l}- \\
-\end{array}$ & - & E & - & $\begin{array}{l}\text { Not made } \\
\text { ED } \times \text { ED } \\
\text { ED } \\
1: 0: 0\end{array}$ \\
\hline
\end{tabular}

* The results for Cross 20 are given in Murfet (1971).

from time to time. EI and L plants are often clearly distinguishable as a result of a gap in the flowering node distribution, but where the distribution is continuous the classes are usually separated by cutting the distribution between nodes 16 and 17 as these nodes represent the most common region of zero or minimum frequency (examples in table 8). Flowering time distributions containing ED and EI or L plants were always discontinuous.

(a) The theory. Three dominant major genes $S_{1}, E$ and $S_{2}$ are proposed to interact as follows. The triple recessive is an ED type. Addition of $S_{2}$ creates an $\mathrm{L}$ type. $E$ is epistatic to $S_{2}$ in terms of flowering node and genotype $s_{1} E S_{2}$ is an EI type. $S_{1}$ is epistatic to $E$ and $S_{1} E S_{2}$ is again $\mathrm{L}$ type as is $S_{1} e S_{2}$. 
$S_{1}$ and $E$ have little or no effect by themselves and genotypes $S_{1} e s_{2}, s_{1} E s_{2}$ and $S_{1} E s_{2}$ are essentially ED. Genotype $s_{1} e S_{2}$ sometimes classifies EI and as the common phenotype is $\mathrm{L}$ such plants are referred to as impenetrant $\mathrm{L}$ type.

(b) The programme. The parents, their proposed genotypes, the crosses made and the expected ratios are shown in table 1 . Line 22 appears in two places because it is impure at the $E$ locus. It is clearly necessary to go beyond $\mathrm{F}_{2}$ to validate these ratios and check on misclassification. For example, the $\mathrm{F}_{2}$ data for Cross 40 (table 7) could easily be mistaken for a $15: 1$ ratio, but $\mathrm{F}_{3}$ data reveal the EI segregates as impenetrant $\mathrm{L}$ plants. The different crosses are not all investigated to the same depth. In Cross 20 an entire $F_{2}$ was genotyped by growing $F_{3}$ and one section was checked through to $F_{4}$. In most other crosses certain sections have been taken beyond $\mathrm{F}_{2}$, e.g. Grosses $26,40,50,114,119$ and 125 were taken to $F_{3}$, Cross 2 (table 7 ) to $F_{5}$ and Cross 57 to $F_{6}$. In the remaining crosses (53,126 and 127) time and space have not permitted the growing of generations higher than $\mathrm{F}_{2}$.

(c) Individual segregation. Individual segregation data are given in table 2. Segregation of the $S_{1} / s_{1}$ pair is typically Mendelian. Segregation of the E/e pair sometimes shows a deficiency of recessives (e.g. Cross 126) which is thought to result from impenetrance of genotype $s_{1} e S_{2}$. Where misclassification is rare (e.g. Cross 20) or revealed by progeny testing (e.g. Cross 114) segregation of the $E / e$ pair is normal. In Cross 114 (table 8 ) the observed $\mathrm{F}_{2}$ numbers of $349 \mathrm{EI}$ and $83 \mathrm{~L}$ plants show a significant deficiency of $\mathrm{L}$ plants $\left(\chi_{1}^{2}=7 \cdot 72^{* *}\right)$. However, $\mathrm{F}_{3}$ progenies of 15 seeds were grown from 18 $\mathrm{F}_{2}$ plants flowering at node 12 of which one plant proved to be impenetrant L type and from all plants flowering at nodes 13,14 and 15 of which all but one were thought to be impenetrant $L$ plants. The corrected $F_{2}$ numbers (table 2) are acceptable as a $3: 1$. Possibly a few more impenetrant L plants would be revealed by progeny testing the remaining EI plants. Analysis of the $S_{2} / s_{2}$ segregations shows a small heterogeneity $\chi^{2}$ and a very large deviation $\chi^{2}$ indicating a significant disturbance. The shortage of recessives is not caused by differential survival as survival was usually better than 99 per cent. Nor is there any suspicion of impenetrance as the genotypes could be confidently distinguished by their flowering time and progeny testing gave no evidence of misclassification.

(d) Foint segregation. The joint segregation data for the three major genes and various markers are given in table $3 . S_{1}$ is linked to the $A$ gene for anthocyanin with a recombination value of about 9 per cent. and $E$ linked to the $P$ gene for pod membrane with a recombination value of about 22 per cent. The linkage of $S_{2}$ is not known, as it recombines freely with the six markers tested $\left(A, I, C y_{1}, V, P\right.$ and $\left.R\right)$. The close linkage between $A$ and $S_{1}$ is also reflected in the $\mathrm{F}_{2}$ data for Cross 57 (128 red L, 12 red EI, 17 white $\mathrm{L}$ and 33 white $\mathrm{EI}$ ) but as this is a $3 \mathrm{EI}: 13 \mathrm{~L}$ ratio individual segregation data for $S_{1}$ and $E$ are confounded. (These numbers were corrected for misclassification by growing progenies of 15 from all EI plants.)

(e) Development of the theory. The three gene scheme may be established as follows. Cross 26 reveals a dominant late gene $S_{1}$ closely linked to the $A$ gene for anthocyanin. Cross 20 establishes a dominant early gene $E$ and a dominant late gene $S_{2}$. Cross 57 confirms $E$ and shows that $S_{1}$ and $S_{2}$ are not identical although they could be allelic. In Cross $119 S_{2}$ and $A$ are segregating in coupling and free recombination between the two loci shows that $S_{1}$ and $S_{2}$ are not alleles. The difference in effect between $S_{1}$ and $S_{2}$ is 


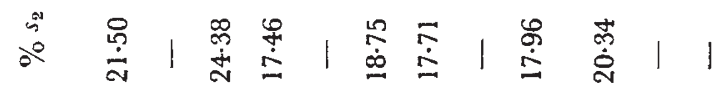

$$
\begin{aligned}
& \text { 幽艾 }
\end{aligned}
$$

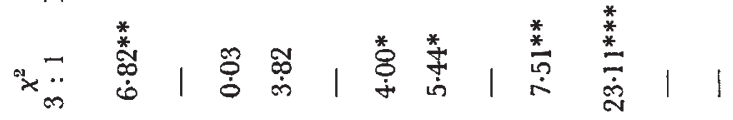

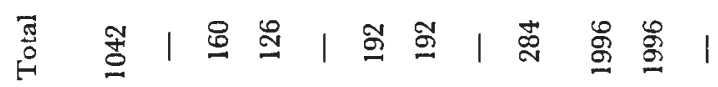

$$
\begin{aligned}
& \text { ๙ }
\end{aligned}
$$

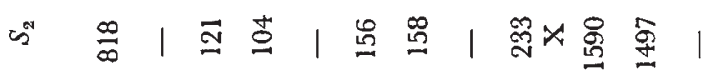

$$
\begin{aligned}
& \frac{\omega^{\infty}}{n^{n}} \\
& \text { 胥 }
\end{aligned}
$$

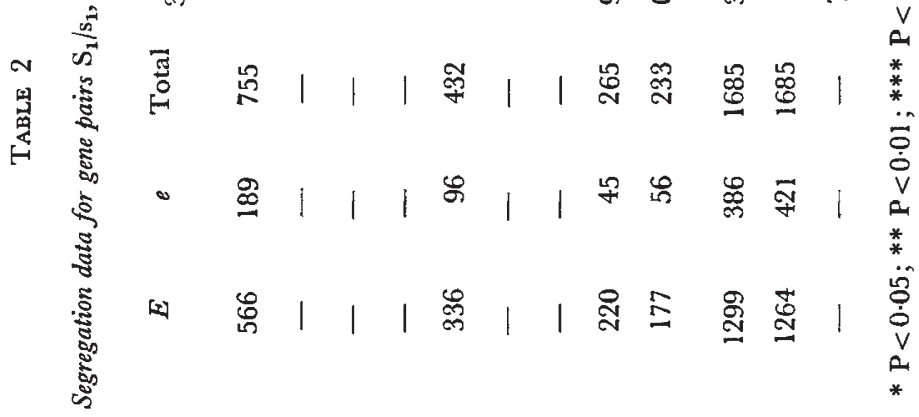

$$
\begin{aligned}
& \text { 爻 }
\end{aligned}
$$

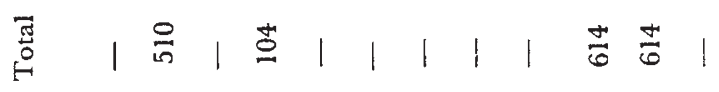

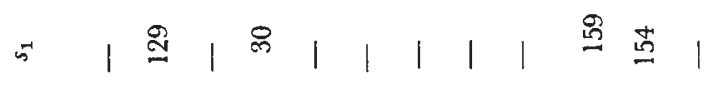

$$
\begin{aligned}
& \text { ज| } \\
& \text { ปั }
\end{aligned}
$$


四 莤

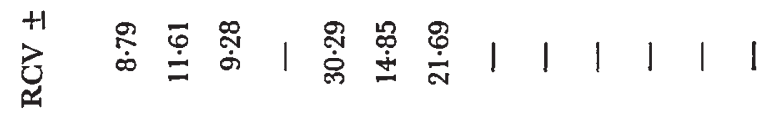

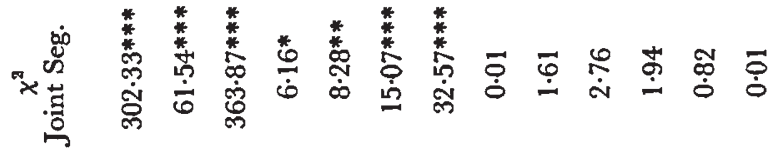

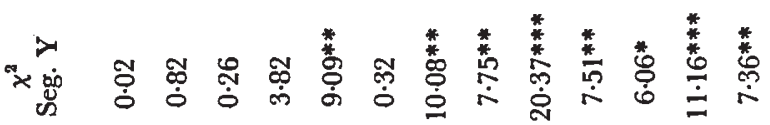

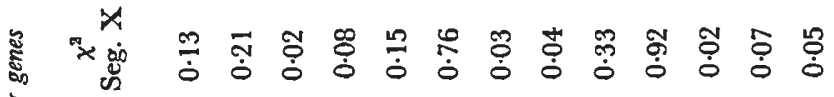

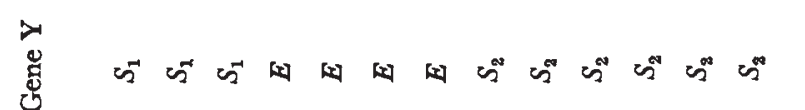

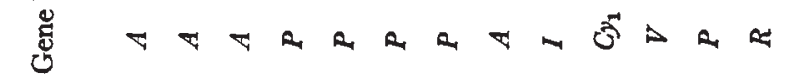

要

䒿 옹

造

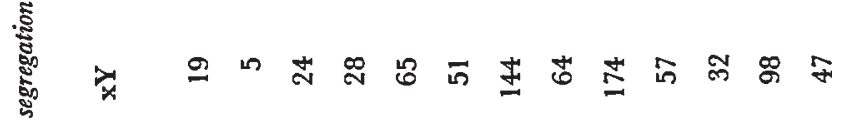

芯

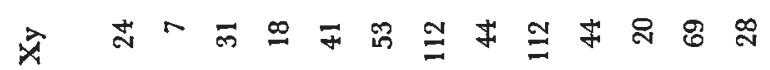

気 8 \%

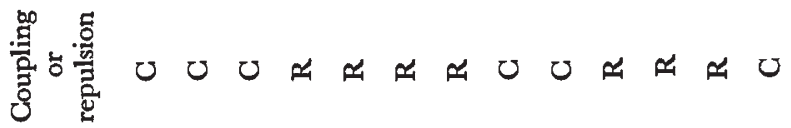

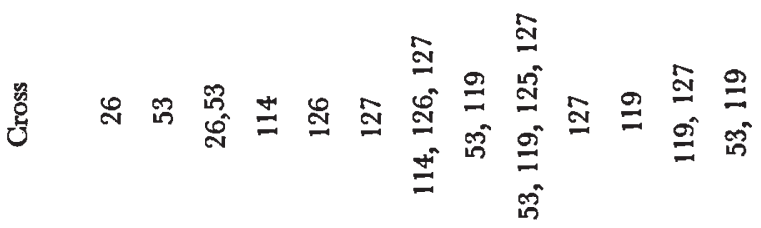


revealed in Cross 125 where $S_{1} e s_{2}$ is found to be an ED type. Only one genotype, $S_{1} E s_{2}$, remains unseen at this point and Cross 53 is thought to confirm the anticipated ED nature of this type. Linkage between $E$ and $P$ is revealed in Cross 114. The remaining crosses (2, 40, 50, 126 and 127) substantiate the theory. Cross 127 (table 8 ) was the last cross to be made and it provides at once a striking example of gene interaction and a confirmation of the theory. Both parents are early and flower in the region of nodes 9-12 $(\mathrm{ED} \times \mathrm{EI})$ but as expected three-sixteenths of the $F_{2}(4 \mathrm{ED}: 9 \mathrm{EI}: 3 \mathrm{~L})$ flower at a high node, one plant flowering as late as node 33.

(f) Pleiotropic effects of $\mathrm{S}_{1}, \mathrm{E}$ and $\mathrm{S}_{2}$. The several crosses reported here confirm the finding from Cross 20 that gene $S_{2}$ opposes flower initiation, floral development and senescence with the result that the total number of internodes, height and yield are substantially increased. In the $F_{2}$ of Cross 119 ED segregates had an average height of $19.3 \pm 1.8 \mathrm{~cm}$. compared with an average of $104.7 \pm 5.8$ for $L$ segregates. (Data from a random sample of 9 plants of each type.) $S_{2}$ increases total height by increasing the number of vegetative nodes (or reproductively ineffective nodes in EI plants) and by prolonging growth after effective flowering commences. This effect on total height is of a different type and order to the effects on internode length reported in the next paragraph and by Barber (1959). Gene $E$ seems principally involved with the regulation of flowering node and its presence is only manifest in the particular combination $s_{1} E S_{2}$. Gene $S_{1}$ is also primarily concerned with flowering node and its presence is most strongly manifest when substituted into genotype $s_{1} E S_{2}$. However gene $S_{1}$, by itself, appears to cause some delay in flower initiation. As the reactions of genotype $S_{1} e s_{2}$ are not yet fully tested, it is not known whether the ability to respond to photoperiod is uniquely conferred by gene $S_{2}$.

\section{TABLE 4}

Data from the $F_{2}$ of Cross 2 showing cross-pleiotropy of genes controlling flowering and internode length. Characters $-F 1=$ node of first initiated flower and $L_{1-9}=$ length of stem in $\mathrm{cm}$. between nodes $I$ and 9 . Phenotypes- $L=$ late, $E I=$ early initiating, $D=$ dwarf and $C=$ cryptodwarf

\begin{tabular}{cccccccc}
\multicolumn{1}{c}{$\begin{array}{c}\text { Photo- } \\
\text { Character }\end{array}$} & period & \multicolumn{2}{c}{ Phenotype $\bar{x} n$} & \multicolumn{2}{c}{ Phenotype $\bar{x} n$} & Students & P \\
FI & 8 & L, D 20.75 & 96 & L, C 22.32 & 28 & $5 \cdot 13$ & $<0.001$ \\
FI & 8 & EI, D 12.59 & 17 & EI, C 11.40 & 5 & $2 \cdot 26$ & $<0.05$ \\
L $_{1-9}$ & 18 & L, D 13.63 & 98 & EI, D 15.22 & 20 & $2 \cdot 43$ & $<0.05$ \\
L $_{1-9}$ & 18 & L, C 27.51 & 23 & EI, C 29.13 & 6 & $1 \cdot 55$ & $0 \cdot 2 \cdot 0 \cdot 1$
\end{tabular}

Genotypes: $\mathrm{L}=S_{1} E S_{2}, S_{1} e S_{2}$ and $s_{1} e S_{2}$ and $\mathrm{EI}=s_{1} E S_{2}$.

$\mathrm{D}=l e C y_{1} c y_{2}^{c}$ and $C=l e c y_{1} c y_{2}^{\circ}$.

In the $\mathrm{F}_{2}$ of Cross 2 under long days late dwarfs were significantly shorter than early dwarfs over the distance between nodes 1 and 9 (table 4). Although not reaching statistical significance the tendency for internodes to be shorter in lates was also seen in cryptodwarfs under long days and again in both classes under short days. It may be noted that the internodes referred to are all below the first flower. As $E$ and $S_{1}$ are both segregating in Cross 2 whilst $S_{2}$ is universally present it would seem that $E$ and/or $S_{1}$ are capable of a pleiotropic effect on internode length although this effect may in fact depend on the simultaneous presence of $S_{2}$. The flowering genes caused changes of internode length up to 12 per cent. of those caused by the major length gene $C y_{1}$. 


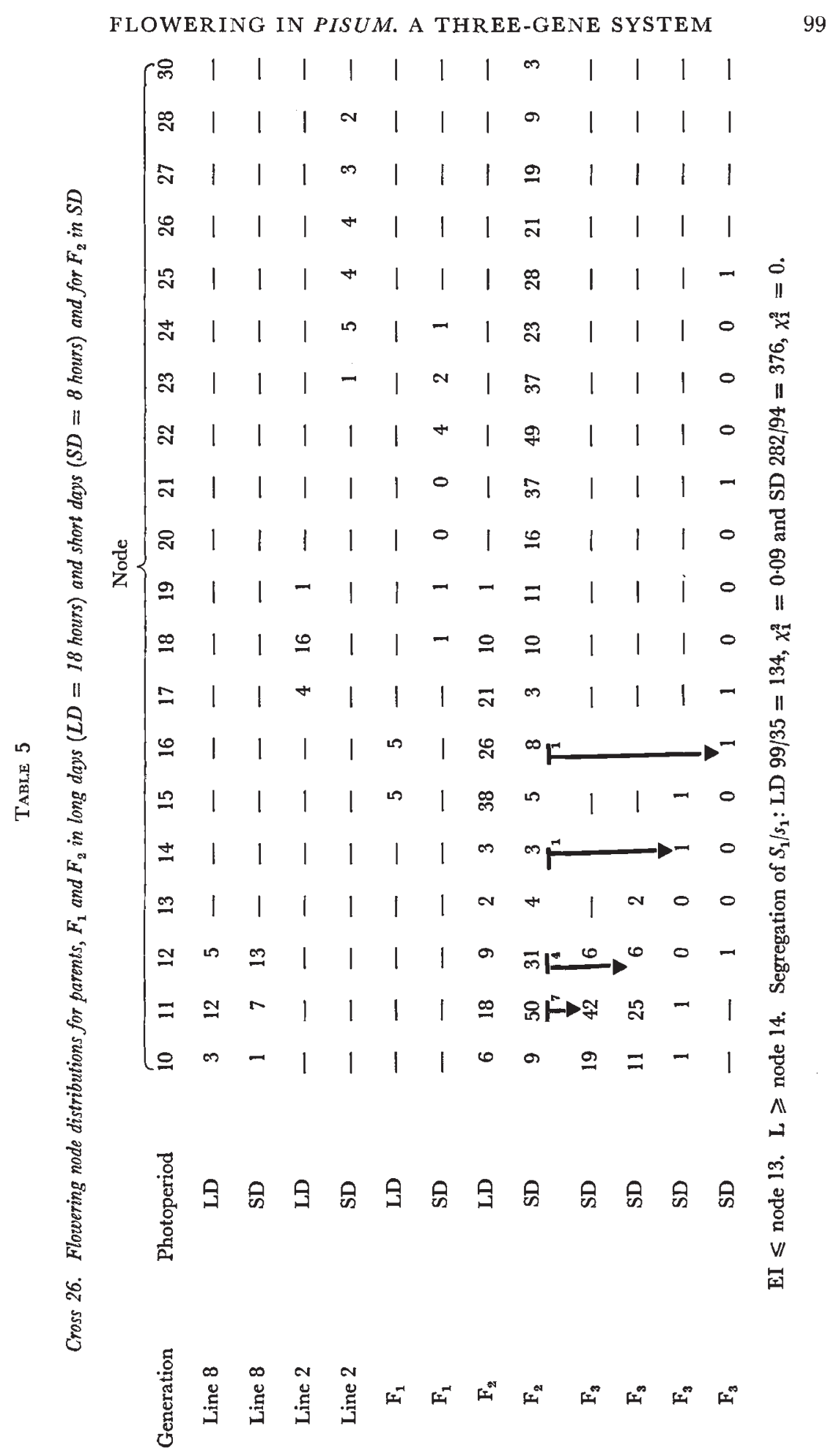


(g) Factors influencing the penetrance of $\mathrm{S}_{2}$. It was reported from Cross 20 that $S_{2}$ showed a tendency towards incomplete penetrance in terms of flowering node whilst maintaining under short days complete penetrance in terms of flowering time. These findings are clearly illustrated by the Cross 119 data (table 6). The $\mathrm{F}_{3}$ descended from $\mathrm{F}_{2}$ plants of genotype $s_{1} s_{1} e e S_{2} s_{2}$ contains a substantial proportion of impenetrant L plants. Although $S_{2}$ plants are continuous with the $s_{2}$ plants in the flowering node distribution in the time distribution there is a clear gap of a fortnight between the two groups. Penetrance was high in some crosses (e.g. 0.96 in Cross 20 and 0.97 in Cross $50)$ but dropped away in other crosses, particularly those involving Line 2 or its descendants, Lines 8, 60 and $6 \mathrm{l}$ (e.g. 0.74 in Cross $119 \mathrm{~F}_{2}$ and less than 0.5 in some families from Cross 57). Apparently Line 2 introduced polygenic modifiers lowering the penetrance of $S_{2}$. It is of interest that Line 2 is an arvense type whilst the parents in the crosses showing high penetrance are of the sativum type.

Further evidence on the penetrance modifiers comes from some small scale selection studies in Cross 57. $\mathrm{F}_{2}$ plants of genotype $s_{1} s_{1} E e S_{2} S_{2}$ are expected to give a $3 \mathrm{EI}: \mathrm{l} \mathrm{L}$ ratio in $\mathrm{F}_{3}$. These $\mathrm{L}$ plants (genotype $s_{1} s_{1} e e S_{2} S_{2}$ ) should breed true in $\mathrm{F}_{4}$, but observed figures were $8 \mathrm{EI}$ and $51 \mathrm{~L}$ plants. The $8 \mathrm{EI}$ plants gave $47 \mathrm{EI}$ and $44 \mathrm{~L}$ plants in $\mathrm{F}_{5}$ and two $\mathrm{L}$ plants gave $12 \mathrm{EI}$ and $28 \mathrm{~L}$ plants. The two $\mathrm{F}_{5}$ groups have significantly different $\mathrm{EI} / \mathrm{L}$ ratios $\left(\chi_{1}^{2}=5 \cdot 23^{*}\right)$ suggesting a significant response to selection for genes modifying the penetrance of $S_{2}$. $\quad F_{6}$ progenies were grown from a few plants in the second $\mathrm{F}_{5}$ and a significant response to selection was again observed.

Cross 119 (table 6) is a monohybrid cross of the type $s_{1} s_{1} e e s_{2} s_{2}$ by $s_{1} s_{1} e e S_{2} S_{2}$ so it may be assumed that any EI plants in the $F_{2}$ are impenetrant $L$ plants and $\mathrm{F}_{3}$ data verify this assumption. Progenies of 12 seeds were grown from all 36 EI plants flowering below node 17 in the $F_{2}$. Fourteen progenies contained no EI plants, and of the remaining 22 only 2 contained more than half EI plants. Of the 36 impenetrant $\mathrm{F}_{2}$ plants, 14 proved to be $s_{1} s_{1} e e S_{2} S_{2}$ (not the same 14 as in the previous sentence) and 22 were $s_{1} s_{1} e e S_{2} s_{2}$. As approximately one-third of the plants are homozygotes, misclassification is apparently not influenced by the dosage of $S_{2}$. This finding is supported by the $\mathrm{F}_{3}$ data where the misclassification rate is closely similar whether the progeny comes from homozygous or heterozygous parents: $22 \mathrm{EI}$ to $145 \mathrm{~L}$ and $31 \mathrm{EI}$ to $172 \mathrm{~L}$ respectively $\left(\chi_{1}^{2}=0.33\right)$.

Finally there is evidence of environmental influence on penetrance. It was shown above that selection over a single generation may cause a significant difference in the rate of misclassification. The $F_{3}$ of Cross 119 was derived solely from impenetrant $F_{2}$ plants and grown under similar conditions to the $\mathrm{F}_{2}$. In spite of this, penetrance rose significantly from 0.74 in $\mathrm{F}_{2}$ to 0.86 in $\mathrm{F}_{3}\left(\chi_{1}^{2}=10 \cdot 5^{* *}\right)$. Presumably some small environmental changes have more than outweighed the absolute effect of selection for reduced penetrance. The relative effect of selection cannot be gauged as $F_{3}$ was not grown from $\mathrm{L}$ plants.

Altogether over 70 impenetrant $s_{1} s_{1} e e S_{2}$-plants have been progeny tested. All progenies contained at least some $\mathrm{L}$ plants. Therefore no strain is available with zero penetrance and on the other hand there seems to be no strain with complete penetrance. Even in Line 53, 2 to 3 per cent. of plants are impenetrant. It is hoped to select a line with penetrance around $0 \cdot 5-0 \cdot 7$. Presumably the flowering situation in these plants is close to the threshold 


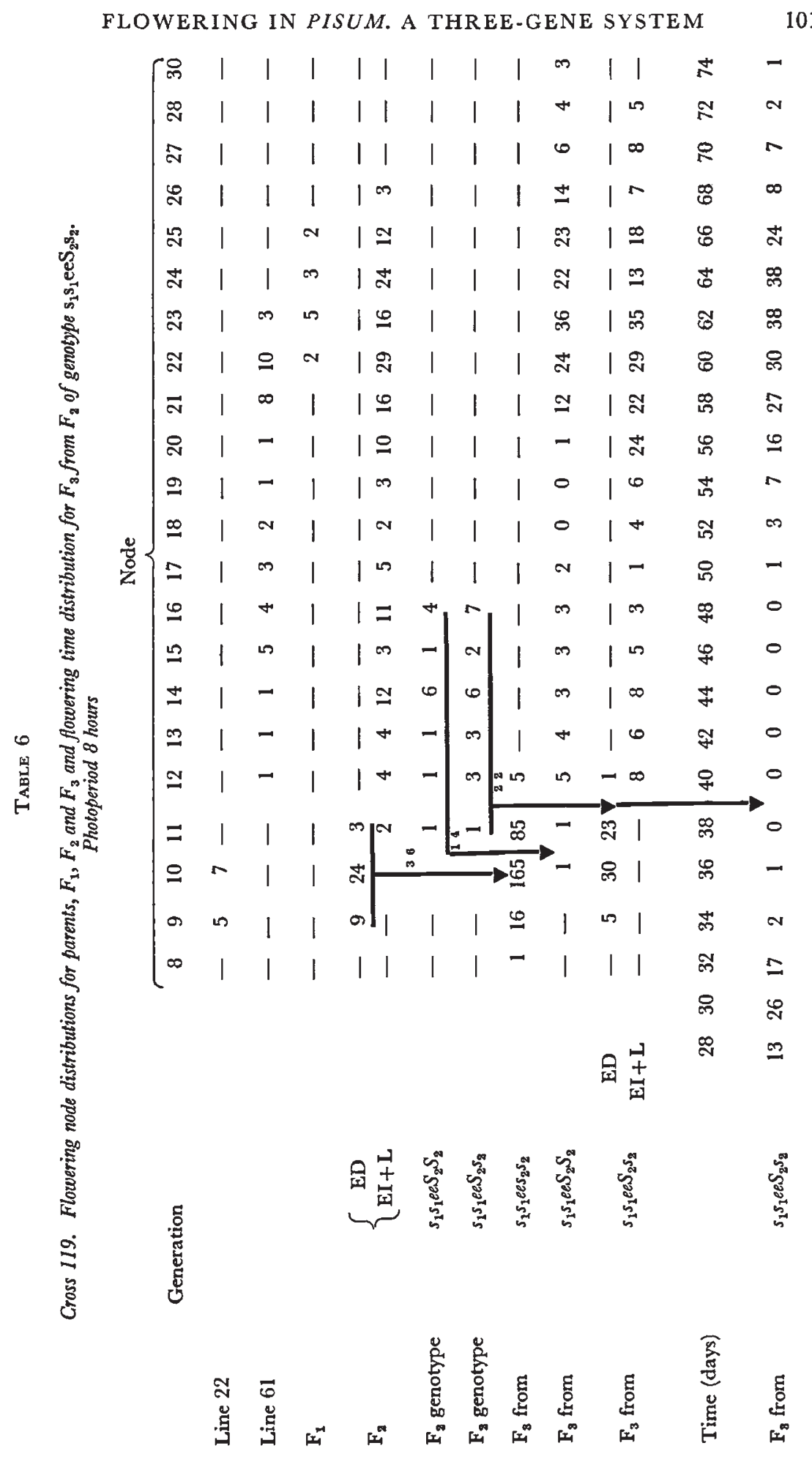


after about node 10 and such a line could be useful as a test plant in flowering studies.

(h) Maternal influence. Influence of the mother plant on flowering node of the offspring is evident in some crosses. For example, in Cross 126 (table 8) two $\mathrm{F}_{1} \mathrm{~s}$ (genotype $s_{1} s_{1} E e S_{2} S_{2}$ ) were generated by direct reciprocal crossing between single plants but there is a difference of more than a node between the reciprocal samples (difference $1 \cdot 2 \pm 0 \cdot 3$ nodes, $t_{18}=3 \cdot 88^{* *}$ ). Again in Cross 125 the $F_{1}$ derived from the early mother $\left(s_{1} s_{1} e e s_{2} s_{2}\right)$ flowered over two nodes later $\left(t_{21}=4 \cdot 64 * * *\right)$ than the direct reciprocal sample derived from the late mother $\left(S_{1} S_{1} e e S_{2} S_{2}\right)$. In both crosses no difference was found between the descendant $\mathrm{F}_{2}$ s. Finally, there is some evidence that $S_{1}-e e s_{2} s_{2}$ plants flower a few nodes later when derived from mothers lacking $S_{2}$ than they do if derived from mothers carrying $S_{2}$ (see section 3(i)). In all three cases described above seed derived from the early mother flowers at a higher node than seed of the same genotype derived from the late mother.

(i) Genotype $\mathrm{S}_{1}-\operatorname{ees}_{2} \mathrm{~s}_{2}$. This genotype appears for the first and only time in Cross $125\left(s_{1} s_{1} e e s_{2} s_{2} \times S_{1} S_{1} e e S_{2} S_{2}\right)$. The $\mathrm{F}_{2}$ segregated into $34 \mathrm{ED}$ and 158 $\mathrm{L}$ plants with a gap of 3 nodes between the classes. These figures show the usual deficiency of $s_{2}$ plants (table 2) but the ED numbers are high enough to eliminate the possibility that $S_{1} e s_{2}$ plants are L. $\mathrm{F}_{2}$ plants were typically ED (flowering node 9-13) but $\mathrm{F}_{3}$ descendants transgressed on the late side $\left(\mathrm{F}_{3}\right.$ range $\left.9-18\right)$. However, all plants had the characteristic ED features of short life-cycle and floral development in short days. There is some evidence that the latest plants were $S_{1} S_{1} e e s_{2} s_{2}$ with $S_{1} s_{1} e e s_{2} s_{2}$ plants intermediate in position. A control $F_{2}$ grown with the $F_{3}$ was similar to the first $F_{2}$ indicating that environmental differences were not responsible for the $F_{3}$ shift. One possibility is that $S_{1}$-ees $s_{2} s_{2}$ plants flower within the usual ED range when derived from mothers carrying $S_{2}$ but slightly later when derived from mothers lacking $S_{2}$. The reactions of this genotype require further study.

(j) Genotype $\mathrm{S}_{1}-\mathrm{EEs}_{2} \mathrm{~S}_{2}$. This genotype appears for the first and only time in Cross 53. As " Line 22 " is impure at the $E$ locus the genotype of the $\mathrm{F}_{1}$ is uncertain. However, this uncertainty need cause no doubts on the nature of $S_{1}-E-s_{2} s_{2}$ plants as an $\mathrm{F}_{1}$ of either $S_{1} s_{1} E e S_{2} s_{2}$ or $S_{1} s_{1} E E S_{2} s_{2}$ is expected to give one-quarter $\mathrm{ED}$ plants in the $\mathrm{F}_{2}$ if an $\mathrm{ED}$ phenotype is assumed for $S_{1}-E-s_{2} s_{2}$. This assumption is verified by the $\mathrm{F}_{2}$ data. The slight deficiency of ED plants is in accord with the usual shortage of $s_{2}$ plants as the L $+\mathrm{EI} / \mathrm{ED}$ figures represent segregation data for the $S_{2} / s_{2}$ pair of alleles (table 2). The observed $\mathrm{F}_{2}$ numbers derived by cutting the flowering node distribution between 16 and 17 (see table 8 ) are 69 red L, 5 white L, 7 red EI, 23 white EI, 16 red ED and 6 white ED. $A$ and $S_{1}$ entered the cross in coupling and their close linkage is reflected in the obviously disturbed red/white ratios in $\mathrm{L}$ and EI plants. The undisturbed ratio in ED plants provides further confirmation of the ED nature of $S_{1}-E-s_{2} s_{2}$ plants. Finally, the $\mathrm{F}_{2}$ was derived from only two $F_{1}$ plants and as the two progenies were almost identical in every respect they were combined in table 8 . The observed numbers of $74 \mathrm{~L}$ and $30 \mathrm{EI}$ plants differ significantly from a $13: 3$ ratio $\left(\chi_{1}^{2}=6.96^{* *}\right)$ but are in good agreement with a $3: 1$ ratio $\left(\chi_{\mathrm{I}}^{2}=0.82, \mathrm{P}>0.30\right)$ indicating a genotype of $S_{1} s_{1} E E S_{2} s_{2}$ for the $\mathrm{F}_{1}$.

(k) Within-class variation. A sample from a genetically pure line of peas shows only a small variation in flowering behaviour; for example, 2-3 nodes 
FLOWERING IN PISUM. A THREE-GENE SYSTEM

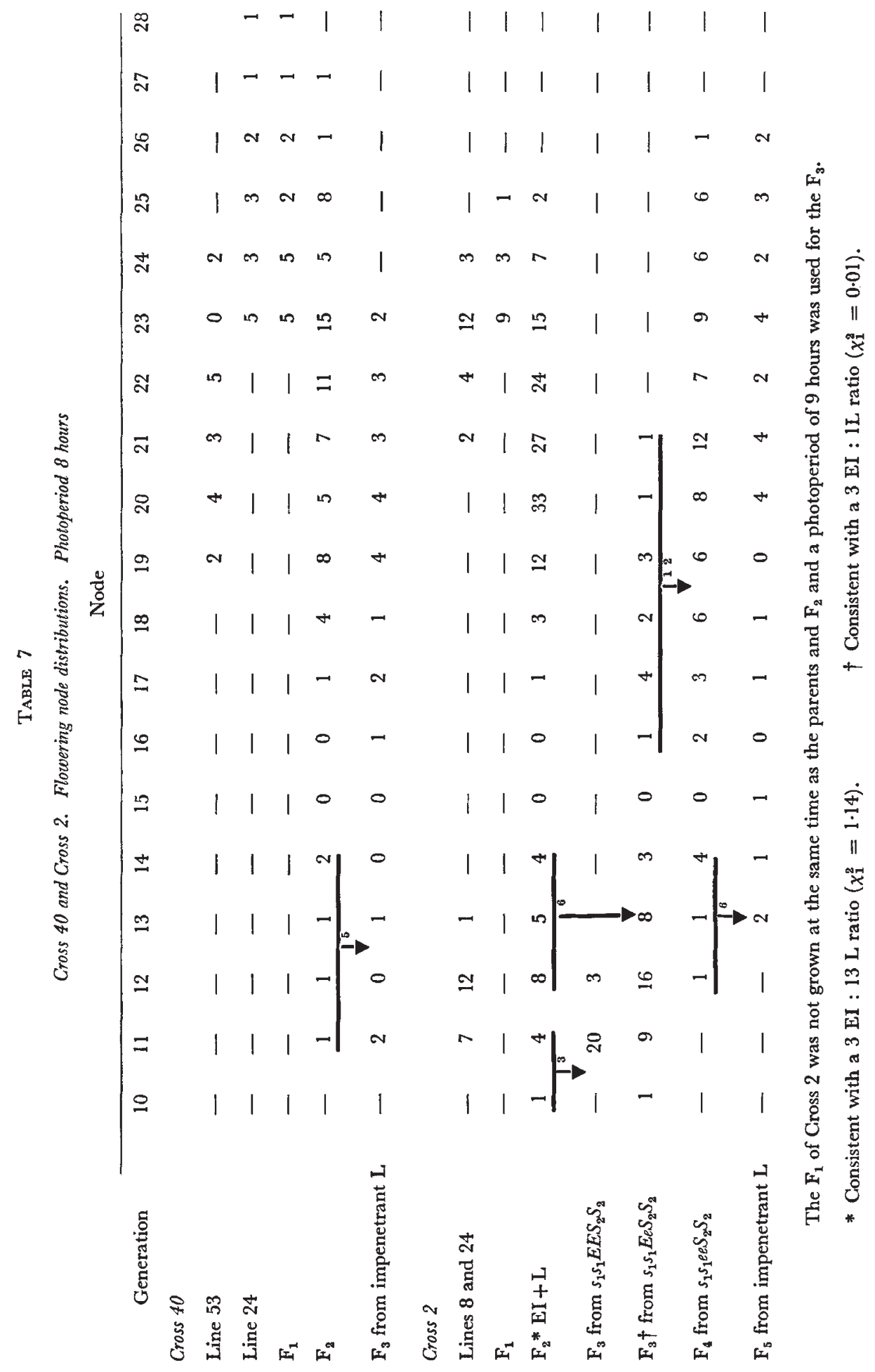


for early lines and 3-6 nodes for late lines. This variation is presumably governed by environmental differences and the homeostatic capacity of the genotype. An $\mathrm{F}_{2}$ usually shows much greater variation within classes than the parents or genetically homogeneous $F_{1}$. This is particularly true of the late class. Several sources of increased within-class variation are illustrated by these crosses.

Firstly, major genes may contribute substantially to within-class variation by dosage and combination effects. This was shown earlier under Cross 20 for genes $E$ and $S_{2}$ and confirmed here in Crosses 2 and 119. A dosage effect for $E$ is seen in the EI plants in the $\mathrm{F}_{2}$ Cross 2 (table 7). As found in Cross $20, S_{2}$ does not show a dosage effect in EI plants. This is illustrated in the $\mathrm{F}_{2}$ of Cross 119 (table 6). The 14 impenetrant $\mathrm{L}$ plants of genotype $s_{1} s_{1} e e S_{2} S_{2}$ flowered at almost exactly the same mean node as the 22 plants of genotype $s_{1} s_{1} e e S_{2} s_{2}-14.21$ and 14.18 nodes respectively. However, L plants in the $\mathrm{F}_{3}$ derived from genotype $s_{1} s_{1} e e S_{2} S_{2}$ flowered significantly later than $\mathrm{L}$ plants derived from genotype $s_{1} s_{1} e e S_{2} s_{2}$ (difference $1 \cdot 2$ nodes, $t_{318}=4 \cdot 89 * * *$ ) thereby confirming the Cross 20 finding that $S_{2}$ does show a dosage effect in L plants. In Cross 125 gene $S_{1}$ apparently increases variation within the ED class by a dosage effect. On an $e e s_{2} s_{2}$ background 0,1 and 2 doses of $S_{1}$ give progressively later plants. Again, gene $S_{1}$ by a combination effect may be at least partly responsible for the fact that Lines 2 and 24 are later than Line 53. All three lines flower within the L class, but 2 and 24 carry $S_{1}$ and $S_{2}$ and 53 carries only $S_{2}$. The same combination effect is almost certain to have contributed to the spread in the $\mathrm{L}$ class of the $\mathrm{F}_{2} \mathrm{~S}$ of Crosses 40 and 2 (table 7).

Secondly, major genes not primarily concerned with flowering may contribute to within-class variation by pleiotropic action. The major internodelength gene $C y_{1}$ is segregating in Cross 2 giving a ratio of 3 dwarf : l cryptodwarf. Flowering node is also segregating giving the ratio $13 \mathrm{~L}: 3 \mathrm{EI}$. In both the $\mathrm{L}$ and EI classes segregation of the $C y_{1} / c y_{1}$ pair has a significant effect on flowering node (table 4). The dominant allele $C y_{1}$ tends to promote flowering in late plants but has the opposite effect in early plants. The same trends were observed in the long-day data, but the differences did not attain statistical significance. The data suggest that $C y_{1}$ may cause changes in flowering node about one-sixth the size of those associated with the major flowering genes.

Thirdly, there is evidence of a quantitative component in the withinclass variation. ED plants show a small amount of transgression particularly on the late side of the class as the early side is virtually bounded at node 9. The ED segregates of Cross 119 illustrate these points (table 6). Although they show only a small increase over the parental range (parent 2 nodes, $\mathrm{F}_{2} 3$ nodes and $\mathrm{F}_{3} 5$ nodes) a regression analysis of $\mathrm{F}_{3}$ progeny mean on $\mathrm{F}_{2}$ flowering node gives a highly significant heritability coefficient $\left(h^{2}=0.38 \pm 0 \cdot 12, \mathrm{P}<0.01\right)$. These ED plants lack all three major dominants. The EI plants in Cross 119 are impenetrant L type plants (genotype $s_{1} s_{1} e e S_{2^{-}}$) and a regression analysis in this case indicated negligible genetic control of flowering node within the group. It was shown earlier that dosage of $S_{2}$ has no effect in impenetrant $\mathrm{L}$ plants. Presumably environment has a relatively large influence as might be expected if the internal situation in the plants is close to the switch point between flowering and vegetative during the time nodes 10 to 16 are being laid down. 


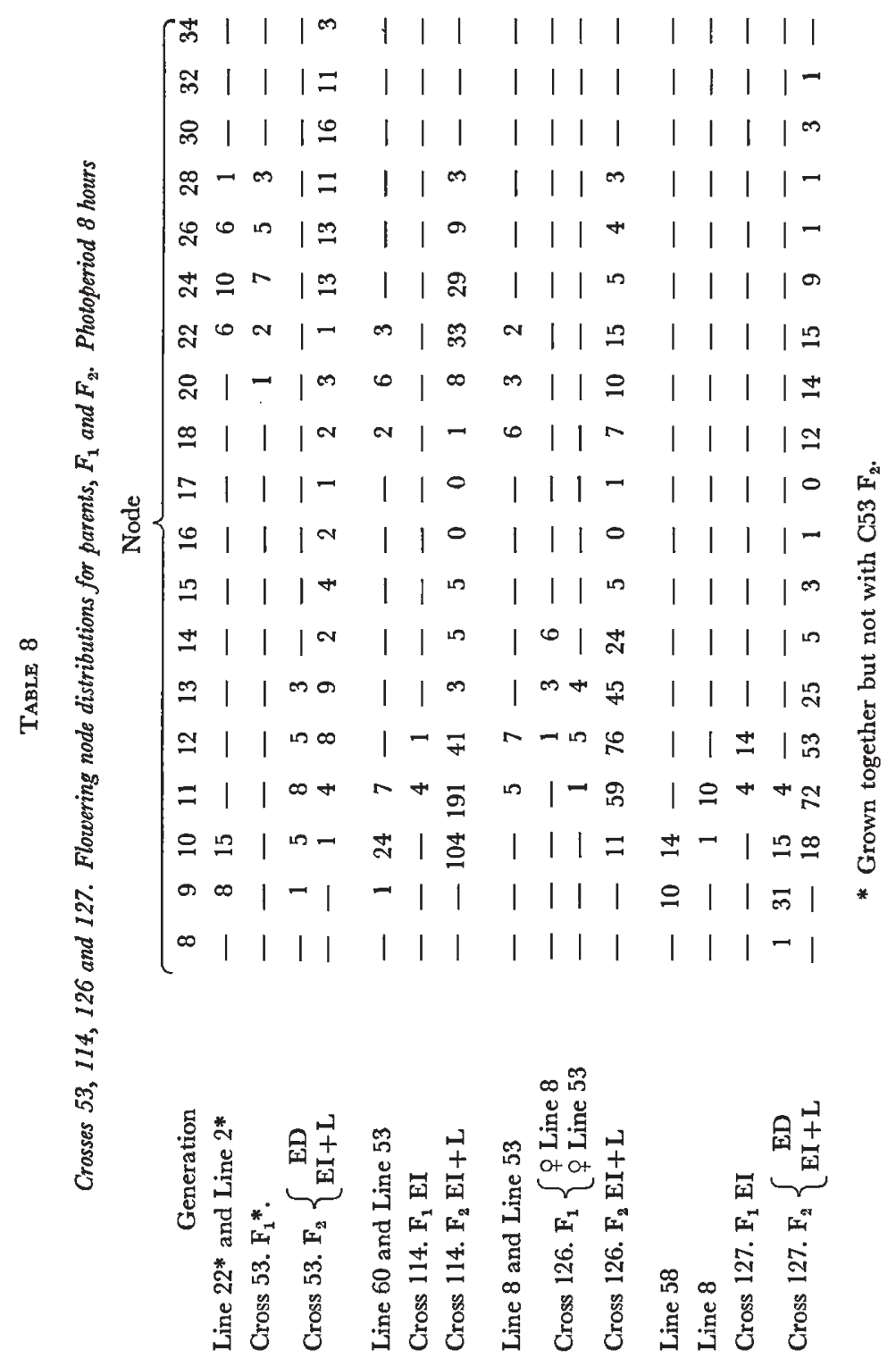


Transgression of parental limits is common in the $\mathrm{L}$ class. However, $\mathrm{F}_{\mathbf{3}}$ data which might reveal the sources of this within-class variation are in general not available. The $\mathrm{F}_{2}$ data for Cross 26 (table 5) suggest a quantitative component. Even the slightly earlier position of the $F_{1}$ in relation to the late parent can be explained by a change in polygenic background. However, a dosage effect for $S_{1}$ would also explain the position of the $\mathrm{F}_{1}$ and much of the spread in the $F_{2}$. The two plants tested at the extreme edge of the distribution were both heterozygotes, but these numbers are far too small to draw any conclusions although they show that $S_{1} s_{1} E E S_{2} S_{2}$ plants are capable of occasionally flowering earlier than node 17. As node 17 is the zero or minimum frequency region separating the EI and L plants in most distributions these plants are in a sense impenetrant $\mathrm{L}$ plants. On the other hand this could be viewed as a reversal of dominance at the $S_{1}$ locus perhaps as a result of polygenic modification. Finally in Crosses 114 and 126 (table 8) the six node transgression at the late end of $\mathrm{L}$ class would seem to indicate polygenic influence.

There is therefore evidence of a quantitative system operating in the absence of all three major dominants and a suspicion of other systems modifying the action of the major genes.

(1) Vegetative reversion in EI plants and the influence of length genes. ED and L plants almost invariably continue in the flowering state once the first flower bud is initiated. In contrast EI plants, whether genuine EI plants of genotype $s_{1} s_{1} E-S_{2^{-}}$or impenetrant L plants of genotype $s_{1} s_{1} e e S_{2^{-}}$, show a marked tendency towards vegetative reversion. For example, in the $\mathrm{F}_{2}$ of Cross 126, 27 per cent. of EI plants showed vegetative reversion for at least one node. Patterns ranged from a typical case such as $11 \mathrm{~F}-14 \mathrm{~F}, 15 \mathrm{~V}$, $16 \mathrm{~F}-\infty$, to an extreme case such as $13 \mathrm{~F}, 14 \mathrm{~F}, 15 \mathrm{~V}-27 \mathrm{~V}, 28 \mathrm{~F}-\infty$. The number of plants which show vegetative reversion was influenced in this $\mathrm{F}_{2}$ by the background of length factors. The $\mathrm{F}_{1}$ was of genotype $l e l e C y_{1} c y_{1} c y_{2}^{c} c y_{2}^{s}$.

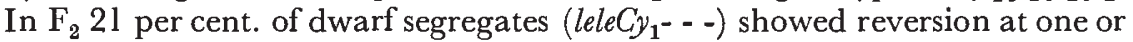
more nodes. With cryptodwarfs (lelecy $\left.c y_{1} c y_{2}^{c}\right) 44$ per cent. showed reversion. The difference is significant at the $0 \cdot 1$ per cent level $\left(\chi_{1}^{2}=18 \cdot 95^{* * *}\right)$. Reversion was most frequent amongst the slender plants $\left(l e l e c y_{1} c y_{1} c y_{2}^{8} c y_{2}^{8}\right)$ but the rate of 56 per cent. is not significantly higher than that for cryptodwarfs $\left(\chi_{1}^{2}=1 \cdot 04\right)$. The above results are consistent with those given in table 4 . Apparently a dwarf background tends to oppose flowering prior to the laying down of node 13. After this time the same dwarf background tends to favour flowering.

\section{Discussion}

(a) The relationship of symbols $\mathrm{Lf}, \mathrm{Sn}, \mathrm{S}_{1}$ and $\mathrm{S}_{2}$. Two gene symbols, Lf and $S n$, are currently in use for dominant late genes in Pisum. The symbol $L f$ was introduced by White (1917) to replace the symbol $A$ used by Hoshino (1915). Hoshino studied flowering time and obtained a continuous bimodal distribution in $\mathbf{F}_{2}$ with a well-defined minimum frequency region. By cutting the distribution at the minimum frequency region he obtained the ratio 6 early : 10 late. He proposed a two-factor hypothesis which is inconsistent, as Wellensiek (1925) has pointed out, for if his $A$ is a factor for late-flowering time, genotype $A a b b$ should be late, not early. Hoshino found linkage 
between late flowering and red flower colour and White states that $L f$ (Hoshino's $A$ ) is linked to factor $A$ for flower colour with an RCV of 12.5 per cent. Lamprecht (1961) places $L f$ in linkage group 1, a short distance from the $A$ locus. He defines $l f$ as giving "First inflorescence at the 9-11th node; early flowering ". Thus White's definition of $L f$ is in terms of flowering time and Lamprecht's definition in terms of flowering node.

Tedin and Tedin (1923) introduced the symbol $S n$. They made several crosses between early and late lines. The distribution of flowering node was bimodal in each $F_{2}$. The minimum frequency region was strongly defined in one case and the numbers in the early and late classes were consistent with a single factor difference with dominance of late flowering. The minima were less clearly defined in the other $\mathrm{F}_{2}$ s but monohybrid segregations were again indicated. The Tedins attributed the segregation to a gene, $S n$, "which in its dominant state increases the number of sterile nodes below the first flower". Gene $A$ was not segregating so there is no indication as to whether their $S n$ is the same as White's $L f$. Barber (1959) used symbol $S n$ in the same sense as the Tedins, but again there is no evidence as to whether the same gene was responsible for the segregation in both cases.

Lamprecht (1961) uses the symbol $L f$ but attaches to it the description of $S n$, which suggests that he considers $L f$ and $S n$ one and the same gene. Can $S_{1}$ or $S_{2}$ be directly identified with $L f$ or $S n$ ? From the linkage data it seems likely that $S_{1}$ was segregating in Hoshino's cross and that the $L f$ on Lamprecht's map is probably $S_{1}$. Also it seems that $S_{2}$ is the same as the $S_{n}$ gene segregating in Barber's Massey by Greenfeast cross as this cross is very probably similar to the present Gross 125. There is however no evidence to identify $S_{2}$ with the original $S n$ which could even be different from both $S_{1}$ and $S_{2}$.

The symbols $L f$ and $S n$ are abbreviations of descriptive terms. The symbols $S_{1}$ and $S_{2}$ are difficult to type, can be mistaken for multiple alleles and erroneously imply that the genes are duplicate factors. All things considered, it would seem desirable to retain the historic symbols but with a new definition. I suggest that from the completion of this paper symbols $L f$ and $S n$ replace symbols $S_{1}$ and $S_{2}$ respectively and thereafter take on the meaning which here attaches to the latter symbols. Uncertainty over gene relationships could be reduced if new types are crossed into a pool of standard varieties. It also seems desirable to use genetically known pure varieties for physiological experiments. The purity and consistency of commercial varieties is certainly suspect in some cases. (Rowlands (1964) suspected heterogeneity in some commercial varieties used in his crosses and commercial Massey proved impure in the present case.)

Over the years the crossing of pea varieties has given little evidence of a dominant early gene. A radiation mutant described by Knavel (1967) is of interest in this respect. The mutant flowered at a higher node than the Early Perfection variety from which it was derived. The $F_{1}$ tended to flower with the early parent. Knavel concluded that back mutation of $s n$ and mutation of " another gene, gene complex or cytoplasmic factor" had occurred. If Early Perfection had genotype $s_{1} E S_{2}$ then a single forward mutation at $E$ might explain his results, although if his first " emerged " flower means first initiated flower, then the values for Early Perfection and the $F_{1}$ are above the usual EI range.

As regards quantitative systems the present work supports proposals put 
forward by Barber (1959). In particular, Cross 119 demonstrates a system which operates in the absence of all three major dominants. Rowlands (1964), using seven pea varieties, has concluded that a simple polygenic system is primarily responsible for the control of flowering along with a major late gene $(S n)$ or effective factor. He takes the view that underlying the superficial control by a major gene (for example of photoperiod response) there is a more complex system directly determining flowering behaviour. The present work portrays the involvement of both major and minor genes but emphasises the primary role of the major genes which are shown to be responsible for most of the between-class variation and a considerable amount of genetic variation within-classes as well. It is of interest that the $C y_{1}$ effect appears to be polygenic if flowering is the only characteristic studied. The major gene nature of $C y_{1}$ is only revealed by the length data.

Finally, the present study does not cover all the genetic variation available in Pisum. For example, the VEI, LHR and VL types described in Murfet (1971) were not included in the present crosses. Lamprecht (1956) has described types flowering at a very low node and Wellensiek (1969) has reported a case of multiple alleles. Also Marx (1968) has described a case in which two complementary genes are responsible for conferring the ability to respond to short days. This case seems to be different from any described here.

(b) The action of genes $\mathrm{S}_{1}, \mathrm{E}$ and $\mathrm{S}_{2}$. Some speculation on the possible action of the major genes may be made on the basis of the cross results. There is not scope here to rigorously explore sundry possibilities in relation to several basic schemes of flowering control. What follows is merely an attempt to deduce a likely model which may be tested in a physiological experiment. Of the three major genes $S_{2}$ has the most widespread effects. It is convenient to start with this gene and assign to it a positive role. Suppose $S_{2}$ is a structural gene responsible for the production of a substance $\left(S_{2}\right.$-substance) which opposes flower initiation, floral development and senescence. Genotype $s_{1} e s_{2}$ flowers around node 9 or 10 . Irrespective of the factor(s) limiting flowering in $s_{1} e S_{2}$ plants prior to node 9 it follows that a high level of $\mathrm{S}_{2}$ substance is responsible for maintaining the vegetative state above this node. Node 9 is laid down about a week after the start of germination, at which time very little green tissue is present. This suggests that the cotyledons are a source of inhibitor. However, in short days $s_{1} e S_{2}$ plants seldom flower before node 20 and may reach 30 vegetative nodes. It seems unlikely that inhibitor from the cotyledons is responsible for maintaining the vegetative state for 30 nodes. Presumably the shoot can also supply $\mathrm{S}_{2}$-substance. Even under short days $s_{1} e S_{2}$ plants normally flower before node 35 , which suggests that the level of inhibitor falls inexorably as the plant ages. Possibly gene $S_{2}$ is switched off or its product destroyed. This suggestion is supported by consideration of floral development in impenetrant $s_{1} e S_{2}$ plants. The lower flower buds are fully suppressed, the middle order buds retarded and the higher buds unhindered.

$s_{1} E S_{2}$ plants initiate flowers at a low node but under short days floral development is suppressed as in impenetrant $s_{1} e S_{2}$ plants. It is clear that although the level of inhibitor is below the threshold at the time these lower flower buds are initiated, a significant level of $S_{2}$-substance is present at the time when these buds would normally undergo development into mature flowers. This suggestion is supported by the fact that $s_{1} E S_{2}$ plants commonly 
show vegetative reversion in the region of nodes 14-17. This behaviour could be explained if gene $E$ reduced the level of $\mathrm{S}_{2}$-substance available from the cotyledons without affecting the action of $S_{2}$ in the shoot. The effects on development and vegetative reversion may then be attributed to $S_{2}$ substance contributed by the shoot. Presumably in $s_{1} E S_{2}$ plants inhibitor levels are very close to the threshold as nodes 14-17 are laid down and this could explain why an internode length gene such as $C y_{1}$ can cause such substantial changes in the rate of vegetative reversion. The length genes are probably not directly concerned with the major components in the flowering system but indirectly influence the level of these components by complex inter-relationships in the metabolic pool. The polygenes lowering the penetrance of $S_{2}$ may possibly act in the same way as gene $E$.

$S_{1}$ counteracts the presence of $E$ and/or penetrance modifiers to ensure that genotypes $S_{1} E S_{2}$ and $S_{1} e S_{2}$ are late. Indications are that inhibitor levels are close to the threshold after about node 10 in $s_{1} E S_{2}$ and impenetrant $s_{1} e S_{2}$ plants. Late flowering in $S_{1} E S_{2}$ and $S_{1} e S_{2}$ plants could be explained if $S_{1}$ lowered the threshold for inhibitor, that is, increased apical sensitivity to inhibitor. This suggestion would also explain why Line $2\left(S_{1} E S_{2}\right)$ and Line $24\left(S_{1} e S_{2}\right)$ are later than Line $53\left(s_{1} e S_{2}\right)$. Again it would explain why $S_{1} e s_{2}$ plants flower at a slightly higher node than $s_{1} e s_{2}$ plants if small quantities of inhibitor are assumed in $s_{2}$ cotyledons.

These speculations lead to a system regulating via an inhibitory component. An alternative model using only promotor may be proposed. $S_{2}$ may suppress the gene for promotor in both the cotyledons and shoot, $E$ may inhibit $S_{2}$ in the cotyledons and $S_{1}$ may cause reduced apical sensitivity to promotor. In the promotor model all genes have a regulatory function. A model involving both promotor and inhibitor may be deduced but further speculation appears unjustified at this stage.

\section{Summary}

1. The genetics of flowering was studied in eight pea varieties representing three distinct classes: ED (early developing), EI (early initiating) and L (late).

2. Class-differences are controlled by three dominant major-genes, $S_{1}$, $E$ and $S_{2}$, which interact as follows. The triple recessive is ED. Addition of $S_{2}$ creates and L-type. $E$ is epistatic to $S_{2}$ in terms of flowering node and $s_{1} E S_{2}$ is EI. $S_{1}$ is epistatic to $E$ and $S_{1} E S_{2}$ is again L. $S_{1} e S_{2}$ is also L. $S_{1}$ and $E$ have little or no effect by themselves and $S_{1} e s_{2}, s_{1} E s_{2}$ and $S_{1} E s_{2}$ are essentially ED.

3. Segregation is normal at the $S_{1}$ and $E$ loci but significantly disturbed at the $S_{2}$ locus with an average of 20 per cent. recessive plants in $\mathrm{F}_{2}$.

4. $S_{1}$ is linked to $A$ with an RCV of 9 per cent. and $E$ to $P$ with an RCV of 22 per cent. $S_{2}$ recombines freely with all markers tested $\left(A, I, C \hat{y}_{1}, V, P\right.$ and $R$ ).

5. Maternal influence was evident in three cases where seed from early mothers flowered later than the same genotype derived from late mothers.

6. The flowering genotype has an influence on internode length.

7. Genotype $s_{1} s_{1} e e S_{2}$ - sometimes classifies EI. Penetrance of $S_{2}$ in terms of flowering node may be modified by both environmental factors and polygenes but it is not affected by dosage of $S_{2}$. 
8. Within-class variation derives from $(a)$ combination and dosage effects for $S_{1}, E$ and $S_{2},(b)$ pleiotropy of other major genes not primarily concerned with flowering such as $C y_{1}$, and $(c)$ various quantitative systems.

9. One quantitative system operates in the absence of dominants $S_{1}, E$ and $S_{2}$ and other systems possibly modify the action of the major genes.

10. Vegetative reversion in EI plants was found to be over twice as frequent in cryptodwarf and slender segregates as in dwarf segregates.

11. A speculative model of gene action is proposed for $S_{1}, E$ and $S_{2}$.

12. It is suggested that the historic symbols $L f$ and $S n$ be redefined to take on respectively the meaning which here attaches to $S_{1}$ and $S_{2}$.

Acknowledgments.-I wish to thank Dr M. Whitten for helpful discussion, Mr R. Buckney for technical assistance and the Rural Credits Development Fund of the Reserve Bank of Australia for a grant in aid.

\section{REFERENCES}

BARBer, H. N. 1959. Physiological genetics of Pisum II. The genetics of photoperiodism and vernalisation. Heredity, 13, 33-60.

Hoshino, y. 1915. On the inheritance of the flowering-time in peas and rice. Four. Coll. Agr. Hokkaido Imp. Univ., Sapporo, 6, 229-288.

KNAVEL, D. E. 1967. A daylength-sensitive, tall-mutant pea. J. of Heredity, 58, 78-80.

LAMPrecht, H. 1956. Ein Pisum-Typ mit grundstandigen Infloreszenzen. Agri Hort. Genet., $14,195-202$.

lamprecht, н. 1961. Die Genenkarte von Pisum. Agri Hort. Genet., 19, 360-401.

MARX, G. A. 1968. Influence of genotype and environment on senescence in peas Pisum sativum L. BioScience, 18, 505-506.

MURfet, I. c. 1971. Flowering in Pisum. Three distinct phenotypic classes determined by the interaction of a dominant early and a dominant late gene. Heredity, 26, 243-257.

rowlands, D. G. 1964. Genetic control of flowering in Pisum sativum L. Genetica, 35, 75-94. TEDIN, H., AND Tedin, O. 1923. Contributions to the genetics of Pisum III. Internode length, stem thickness and place of the first flower. Hereditas, 4, 351-362.

wellensiek, s. J. 1925. Genetic monograph on Pisum. Bibliog. Genet., 2, 343-476.

WELlensiek, s. J. 1969. The physiological effects of flower forming genes in peas. Z. Pfl. Physiol., 5, 388-402.

white, o. E. 1917. Studies of inheritance in Pisum II. The present state of knowledge of heredity and variation in peas. Proc. Amer. Phil. Soc., 56, 487-589. 